\title{
High intensity focused ultrasound: a future alternative to surgery for the treatment of localized pancreatic tumors?
}

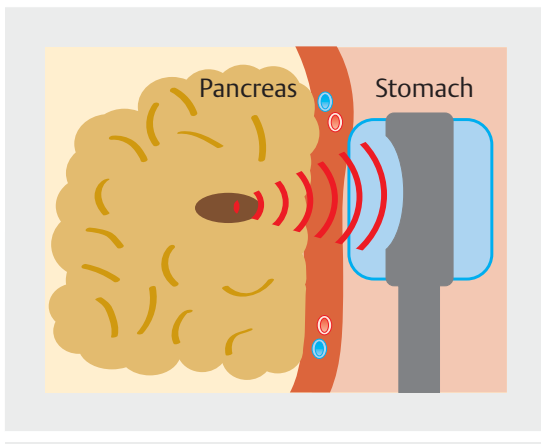

- Fig. 1 High intensity focused ultrasound device.

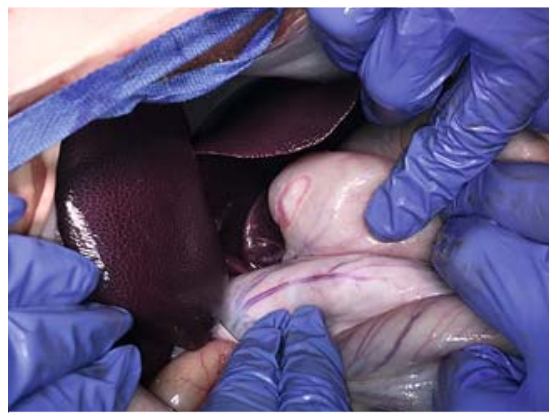

Fig. 3 Necrotic lesion in the sonicated gastric wall.

Focal destruction procedures are a promising alternative to surgery for the treatment of pancreatic tumors $[1,2]$. The high intensity focused ultrasound (HIFU) device allows ultrasound beams to be concentrated at the focal point of the transducer leading to an increase in temperature and tissue necrosis without damaging interposed tissues ( $\bullet$ Fig. $\mathbf{1}$ ). In order to target the pancreas while avoiding sound reflection on gastric air, an endoscopic ultrasound probe was developed (Vermon, Tours, France). This endoscopic approach allows the HIFU probe to be placed in contact with the posterior wall of the stomach. The probe combines an HIFU transducer and an ultrasound imaging probe. A balloon allows cooling of the transducer and the wall of the stomach.

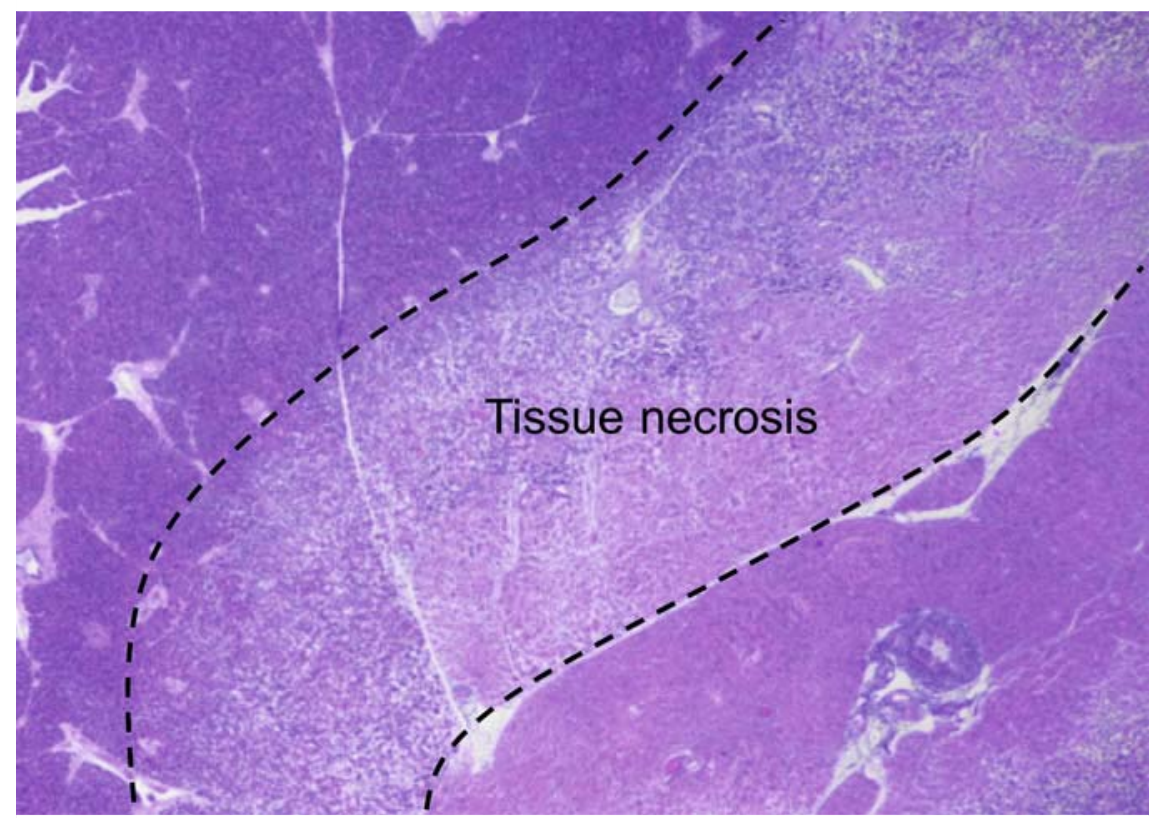

- Fig. 2 Anatomopathological analysis of the targeted pancreas.
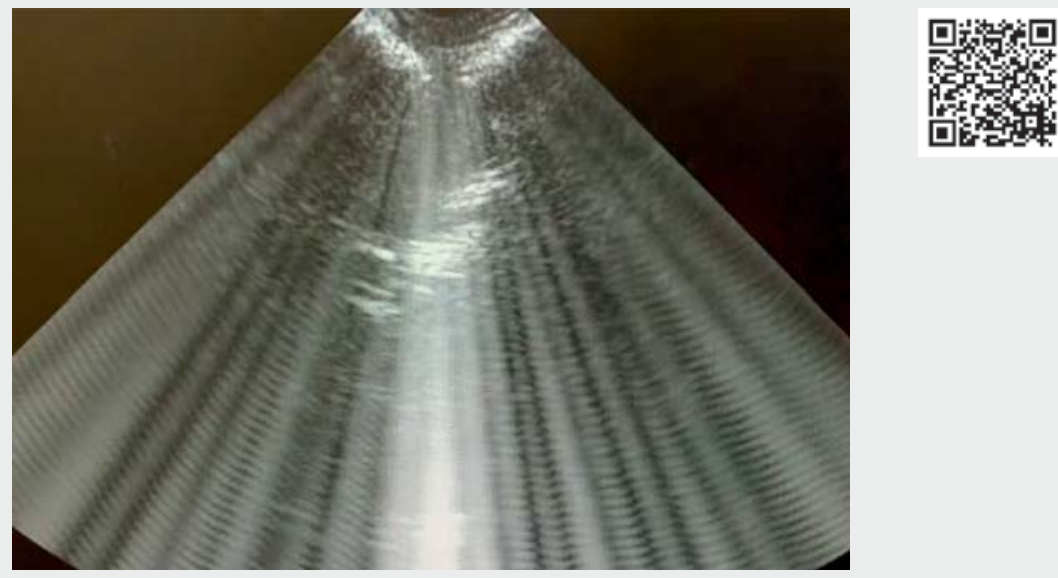

$\nabla$ Video 1 High intensity focused ultrasound for treatment of localized pancreatic tumors.

Experiments were conducted on five anesthetized pigs ( $\vee$ Video 1$)$. The pancreas was first located using the ultrasound imaging part of the probe. Overall, 16 transgastric HIFU sonications were performed on the tail of the pancreas. Each sonication was focused $40 \mathrm{~mm}$ from the probe for 45 seconds. Acoustic power was set to $64 \mathrm{~W}$. Macroscopic examination of the pancreas of all pigs identified a total of seven necrotic areas with mean maximum diameter of $9.4 \pm 3.5 \mathrm{~mm}$. An 
anatomopathological analysis confirmed the irreversible destruction of tissues in the necrotic areas (\$Fig.2). Only one necrotic lesion was found in the sonicated gastric wall (> Fig. 3 ).

To summarize, it is possible to induce areas of pancreatic necrosis using the HIFU device and endoscopic ultrasound probe, with a low complication rate. At present, this technique lacks reproducibility; however, eventually all parts of the pancreas could be accessible for treatment by HIFU ablathermy, making the endoscopic route more beneficial than extracorporeal procedures.

Endoscopy_UCTN_Code_TTT_1AS_2AD

Funding

Société Française d'endoscopie digestive, Hospices Civils de Lyon

dx.doi.org/10.13039/501100006451

\section{Competing interests}

The authors declare that they have no conflict of interest.
The authors

Martin Fabritius ${ }^{1,2}$, Thomas Lambin ${ }^{1,2}$, Elodie $\mathrm{Cao}^{2}$, Jade Robert ${ }^{2}$, Laurent Milot ${ }^{2,3}$, Cyril

Lafon $^{2}$, Mathieu Pioche ${ }^{1,2}$

1 Department of Endoscopy and Gastroenterology, Pavillon L, Edouard Herriot Hospital, Hospices Civils de Lyon, Lyon, France

2 Université Lyon 1, Centre Léon Bérard, INSERM, LabTAU, Lyon, France

3 Department of Radiology, Edouard Herriot Hospital, Hospices Civils de Lyon, Lyon, France

\section{Corresponding author}

\section{Martin Fabritius, MD}

Endoscopy Unit, Digestive Disease Department, Pavillon L, Edouard Herriot Hospital, 69437 Lyon Cedex, France martin.fabritius@chu-lyon.fr

\section{References}

[1] Marinova M, Huxold H, Henseler J et al. Clinical effectiveness and potential survival benefit of US-guided high-intensity focused ultrasound therapy in patients with advanced-stage pancreatic cancer. Ultraschall Med 2019; 40: 625-637

[2] Dababou S, Marrocchio C, Rosenberg] et al. A meta-analysis of palliative treatment of pancreatic cancer with high intensity focused ultrasound. J Ther Ultrasound 2017; 5: 9
Bibliography

Endoscopy 2022; 54: E17-E18

DOI 10.1055/a-1338-0293

ISSN 0013-726X

published online 16.2.2021

(c) 2021. Thieme. All rights reserved.

Georg Thieme Verlag KG, Rüdigerstraße 14,

70469 Stuttgart, Germany

\section{ENDOSCOPY E-VIDEOS \\ https://eref.thieme.de/e-videos}

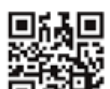

Endoscopy E-Videos is a free access online section, reporting on interesting cases and new

techniques in gastroenterological endoscopy. All papers include a high quality video and all contributions are freely accessible online.

This section has its own submission website at https://mc.manuscriptcentral.com/e-videos

\section{CORRECTION}

High intensity focused ultrasound: a future alternative to surgery for the treatment of localized pancreatic tumors?

Fabritius M, Lambin T, Cao E et al. High intensity focused ultrasound: a future alternative to surgery for the treatment of localized pancreatic tumors? Endoscopy 2021, 53:

10.1055/a-1338-0293

In the above-mentioned article, Thomas Lambin has been included as author. This was corrected in the online version on February 19, 2021. 